\title{
Systematization Approach for the Development and Description of an Internal Crowdsourcing System
}

\author{
Marco Wedel and Hannah Ulbrich
}

\begin{abstract}
There is a need for a scientific and theoretical foundation in the description of internal crowdsourcing systems with binding, consensus-based terminologies and descriptions. (How) Can the already described subcategories and aspects of an IC System be meaningfully described and placed in an orderly overall relationship? What needs to be added to existing system descriptions, if at all? The present article concentrates on identifying existing descriptions and definitions in connection with approaches to systematize the development of an internal crowdsourcing system (Some aspects of this article will also be published in German. Please be referred to: Daum, M.; Wedel, M.; Zinke-Wehlmann, C.; Ulbrich, H. (ed.) (2020): Gestaltung vernetzt-flexibler Arbeit. Beiträge aus Theorie und Praxis für die digitale Arbeitswelt. Berlin: Springer Vieweg). Since the phenomenon itself eludes allocation to an exclusively dedicated academic discipline, it seems appropriate to choose interdisciplinary approaches and to build on existing theoretical and terminological approaches from related sciences.
\end{abstract}

Keywords Crowdsourcing · Internal crowdsourcing · Corporate crowdsourcing · Governance · Management · IC System · Crowdsourcing frameworks · Theory frameworks $\cdot$ Crowdsourcing theory

\section{Introduction to the Present Status of Crowdsourcing Theory}

Based on what Sabatier (2007, p. 323) and Schlager (1995) stated for theories pertaining to the policy process, one could characterize the current state of crowdsourcing theory, including internal crowdsourcing (IC), as mountain islands

M. Wedel $(\bowtie) \cdot$ H. Ulbrich

Institute for Vocational Education and Work Studies, Technische Universität Berlin, Berlin, Germany

e-mail: marco.wedel@tu-berlin.de; hannah.ulbrich@tu-berlin.de 
of empirical work, intermingled with, and occasionally attached together by foothills of shared methods and concepts, merely hinting at distant theoretical ideas (see also Wedel 2016, p. 13). The lack of theoretical foundations becomes clear in the terminological vagueness to be found in the existing empirical and descriptive works on IC.

As will be shown here, the reason for this is that, on the one hand, various independently applied terminologies supposedly refer to the same phenomena, and, on the other hand, certain applied vocabulary neglects its ascribed meaning. Consequently, the occupation with fundamental research questions regarding, e.g. regulating crowdsourcing by way of academic discourse is impeded, because respective contributions stand as isolated, non-related inputs rather than further augmentations to and of an ongoing scientific discussion.

Given this heterogeneity and fuzziness of - first and foremost- the applied terminologies in the context of IC, and the confusion it creates, there is a need for a scientific foundation, that is, theoretical fundamentals that can be applied to arrive at a description of an IC System with binding, consensus-based categories. Of course, the lack of definitional clarity is not surprising given the relatively recent nature of the IC phenomenon. Due to its growing (scientific) popularity, however, it is necessary to start a discourse on system-defining theoretical foundations for IC in order to avoid a nonbinding, in the worst case self-referential, coexistence of a rapidly growing stock of research. Since the phenomenon itself eludes allocation to an exclusively dedicated scientific discipline, it seems appropriate to choose interdisciplinary approaches and - without having to reinvent the wheel-to build on existing theoretical and terminological approaches from related academic fields.

Building on Pohlisch (here), a reasonable first starting point to identify theoretical cornerstones for a system-description-to-be is provided by recently published governance frameworks and by identifying the terminological range and clarity within the existing descriptions of steering activities in connection with crowdsourcing (crowdsourcing management). The following example illustrates the nature of the problem within the referred-to discourse: terms such as 'governance' and 'process management' are applied interchangeably, while approaches, such as sociotechnical systems theory (STS), are introduced on top of that (Blohm et al. 2018; Knop et al. 2017). And, terms like 'control' and 'governance' are used synonymously to describe such different things as role, task, structure and technology descriptions, framework conditions, general mechanisms or task assignments, furthermore also task definitions, task types, evaluation mechanisms, qualification and incentivization mechanisms as well as general regulations and agreements (Alam and Campbell 2013; Blohm et al. 2018; Knop et al. 2017; Zogaj and Bretschneider 2014; Zuchowski et al. 2016).

Although a binding system description for IC should address, reference and explain all these subareas, the individual sub-dimensions in and of themselves cannot, however, become the sufficient descriptive feature of the whole, in this case an IC System. For a future, target-oriented (academic) discourse, the subcategories and aspects of an IC System need to be meaningfully described and placed in an orderly overall relationship. 
The overarching question is therefore: (How) Can the already described subcategories and aspects of an IC System be meaningfully described and placed in an orderly overall relationship? What needs to be added to the existing system descriptions, if at all?

The present article concentrates on identifying existing descriptions and definitions in connection with approaches towards a systematization of the development of an internal crowdsourcing system.

\section{Discussion}

\subsection{Description Approaches and Control Principles of Crowdsourcing}

Approaches towards describing systemic structures usually find their starting point in the analysis of identifiable framework conditions which, as such, provide a first indication of phenomenon-immanent characteristics. Pedersen et al. (2013) identified the elements 'problem', 'people', 'governance', 'process', 'technology' and 'outcome' as relevant categories for the academic description and analysis of crowdsourcing with regard to initial conceptual foundations. Based on a structured analysis of the literature on internal crowdsourcing, Zuchowski et al. (2016, $168 \mathrm{f}$.) adopt this six-component logic and describe respective framework conditions. Accordingly, the problems component, governance component, people component, IT component, process component and outcome component become the descriptive characteristics deemed to be sufficient for a basic IC Framework (Zuchowski et al. 2016, ibid.).

In brief, the 'problems component' addresses the dimension of problems which can be solved by crowdsourcing including considerations with respect to the degrees of complexity and differentiation that can be taken up, considered and dealt with in a crowdsourcing procedure. The 'governance component' according to Pedersen et al. (2013, p. 582) is based on steering considerations under the premise of achieving a desired goal. According to the Zuchowski et al. (2016, p. 169), governance describes general management tasks. Pedersen et al. (2013, p. 581) subsume under 'process' a series of measures that must be realized by parties involved in a crowdsourcing project in order to solve a specific problem or achieve a specific goal. Following Zuchowski et al. (2016, p. 169), process can be divided into the phases 'preparation', 'implementation', 'evaluation' and 'solution/decision'. The element 'people' addresses roles and role models and social conditions for the implementation of crowdsourcing activities. The heading 'Technology' or 'IT' deals with information technology conditions for crowdsourcing. The 'outcome' element is the final component of the proposed concept, which pools all aspects concerning results of the crowdsourcing process (Pedersen et al. 2013, 582 ff.; Zuchowski et al. 2016, 168 f.). 
Knop et al. (2017) take on the elements described above and order them under the theoretical lens of socio-technical systems. This systematization approach follows a premise outlined by Baxter and Sommerville (2011) whereupon the system to be described reflects a process that takes into account both social and technical factors that have an original influence on the functionality and use of IT-based systems. Beese et al. (2015) refer in this context to the enormous complexity of sociotechnical systems, which depend on a multitude of often non-linear and dynamic mechanisms relating to both social and technical subsystems (Knop et al. 2017, 2 f.). Within this approach, IC is described as a socio-technical system that can be divided into the five components 'Actors', 'Task', 'Structure', 'Technology' and 'Environment' (Knop et al. 2017, p. 3).

While the elements 'Technology/IT', 'People/Actors' and 'Problem/Task' seem to be more or less congruent in all their proposed functional aspects (or such a congruence is, at least, assumed for now, see: Pedersen et al. 2013; Zuchowski et al. 2016), Knop et al. (2017) renounce the elements 'Outcome', 'Process' and 'Governance' in favour of the elements 'Environment' and 'Structure'. Knop et al. (2017, p. 3) defining the element 'Structure' as

Systems of communication, systems of authority, and systems of workflow. It further includes both the normative dimension, that is, values, norms, and general role expectations, and the behavioural dimension, that is, the patterns of behaviour as actors communicate, exercise authority, or work within the internal crowd.

It should be argued at this point that the element 'structure', insofar as more far-reaching and differentiating descriptions of the categories presented here are missing, is a synthesis of considerations by Pedersen et al. (2013) and Zuchowski et al. (2016) in relation to 'process' and 'governance'. A statement or explicit reference to the latter in relation to the extension or modification of the selected categories by Knop et al. (2017) could not be found.

Despite all the differences, the approaches outlined above towards describing an IC System clearly demonstrate an attempt to come up with a first functional differentiation. Furthermore, in the selected description categories, a functional alignment with respect to the application of IC becomes apparent, revealing an application-oriented perspective. Problems, solutions, desired goals, tasks, results and evaluations, in order to include some of the applied descriptions, arise terminologically from an economic or practice-oriented design framework. The research work on external and internal crowdsourcing has in common that it pursues a strongly innovation-centred approach, which is accompanied by description categories that are characterized by economic and business management aspects (Ebner et al. 2009; Keinz 2015; Garcia Martinez 2017; Palin and Kaartemo 2016; Zhu et al. 2014, 2016; Zuchowski et al. 2016; Thuan 2019). This also results in the circumstance that many research projects in the context of (internal) crowdsourcing are 'applied science' projects which, as consortia, often focus primarily on economic perspectives (Blohm et al. 2018; Zhu et al. 2016; Thuan 2019). It is this aspect that explains the inherent logic of theoretical IC System descriptions within the empirical research, where research objectives are generally oriented towards understanding 
organizational practices, coordination mechanisms and organizational patterns, control and leadership mechanisms as well as management implications for innovation generation.

For Pedersen et al. (2013), Zogaj et al. (2014) and Zuchowski et al. (2016), it seems clear that this application-oriented, target-control aspect of crowdsourcing activities is suitable for describing one fundamental aspect of an IC System which should be labelled 'governance'. According to Pedersen et al. (2013, p. 582)

Governance is the actions and policies employed to effectively manage the crowd and steer them toward the desired solution.

Based on this, Pedersen et al. (2013, p. 582) draft four governance challenges ('Effective task break-down mechanism', 'Effective task integration mechanisms', 'Effective incentive mechanism', 'Effective quality assurance system') and five governance mechanisms ('Right Incentive Mechanism', 'Managing Submissions', 'Loss of Control', 'Quality of the Ideas', 'Creating Trust'). Why challenges are described as mechanisms, and mechanisms with, for example, 'loss of control' are summarized as challenges, seems to be due to an erroneous table heading, but ultimately cannot be understood. Apart from the quote above, Pedersen et al. (2013) offer no further matter suitable for an ongoing consolidation with respect to describable system fundamentals or distinctions with respect to the meaning of governance.

Zogaj and Bretschneider (2014) approach the governance problem by analysing the implementation of crowdsourcing on the basis of three practical examples in order to obtain information with regard to governance mechanisms in particular. Based on Dahlander et al. (2008, p. 118), governance mechanisms determine the nature and quality of participation in different 'online communities' to promote and generate innovation. In the context of citing Dahlander et al., Zogaj and Bretschneider (2014, p. 4) state, that

[...] governance is carried out by means of different mechanisms, so-called governance mechanisms (Dahlander et al. 2008).

In order to describe governance itself, they essentially adopt a definition proposed by Markus (2007, p. 152) which seems to be based on a quotation by Lynn et al. (2001, p. 6). Zogaj and Bretschneider (2014, p. 4) define governance in crowdsourcing accordingly as a

[...] means of achieving the direction, control and coordination of wholly or partially autonomous individuals on behalf of a crowdsourcing initiative to which they (jointly) contribute.

While Zogaj and Bretschneider base their definition on Markus, who adapts it for the context of Open Source Software (2007, p. 152), Markus for his part refers to Lynn et al, who explicitly refer to 'public-sector applications' for their definition framework (2001, p. 5). This provides a first indication of the origins of the scientific and theoretical reference framework in the application of the governance concept for crowdsourcing. Dealing with 'public-sector applications' describes a research focus originating in the political and administrative sciences. 
Zuchowski et al. (2016, p. 171), who explicitly refer to the definition offered by Pedersen et al. (2013) and Zogaj and Bretschneider (2014), continue to stress the control and management-based understanding in their definition approach:

We understand as 'governance' all actions and policies used to govern, manage, and steer the crowd and internal crowdsourcing.

In addition, they introduce the category 'crowdsourcing governance tasks'. Some of a total of six governance tasks are assumed to apply exclusively to internal crowdsourcing only. This is true for the first category '(a) management of corporate culture and change'. The other categories are titled '(b) incentive design; (c) task definition and decomposition; (d) quality assurance; (e) community management; and (f) management of regulations and legal implications' (Zuchowski et al. 2016, 171 f.). In summary Zuchowski et al. (2016, p. 172) conclude, that

[...] the above discussion shows important differences between governance of internal crowdsourcing and external crowdsourcing and hierarchy-based work.

Notably, a functional differentiation of governance in crowdsourcing is made at this point, which is based on the scope of external in contrast to internal crowdsourcing. This need for differentiation based on structural differences between external and internal crowdsourcing is also supported by Knop et al. (2017, p. 2).

A final governance definition offered for IC is made by Blohm et al. (2018, p. 7) who, based on an analysis of governance mechanisms in 19 case studies, arrive at the following understanding:

In crowdsourcing, governance involves structuring roles and responsibilities, formal and informal rules, standards and regulations, outcome control measures, communication processes, or matters of task allocation in order to achieve the crowdsourcer's goal.

On this basis, Blohm et al. (2018, 7 f.) define six classes-'Task Definition', 'Task Allocation', 'Quality Assurance', 'Incentives', 'Qualification' and 'Regulation' within which 21 governance mechanisms can be located and described. The authors' reference to previous studies $(2018$, p. 8), which have led to the clear identification of these 21 mechanisms, cannot be reproduced because:

In order to ensure the possibility of a blind review, we do not cite these studies.

Based on the above, some subcategories and aspects for the description of a crowdsourcing system can be identified. (1) Crowdsourcing as a system or concept consists of framework conditions, elements or components (Pedersen et al. 2013; Zuchowski et al. 2016). These frameworks, elements and components, as Knop et al. (2017) propose, can be interpreted through the lens of socio-technical systems theory, which is a first reference to suitable theory frameworks. (2) All approaches are united in that they presuppose the attribution of a system-inherent manoeuvrability towards a 'desired solution' (Pedersen et al. 2013, p. 582) that implicitly defines the purpose of the system, namely, to achieve 'the crowdsourcer's goal' (Blohm et al. 2018, p. 7). (3) In order to achieve this, as described and sufficiently quoted above, governance is required. (4) Governance, in turn, can be subdivided into individual mechanisms (Zogaj et al. 2014; Blohm et al. 2018) or 
'crowdsourcing governance tasks' (Zuchowski et al. 2016, p. 171). (5) A functional and structural distinction is made between external and internal crowdsourcing, including in the application of governance mechanisms (Zuchowski et al. 2016; Knop et al. 2017).

\subsection{In the Governance Trap?}

The identification of proposed description categories only reflects first premonitions of what it is that constitutes an IC System. If, however, the aim was to achieve definitional and conceptual clarity in order to come up with a meaningful and orderly overall set of aspects that constitute a dependable IC System as a cornerstone for a goal-oriented academic discourse, this clarity is still lacking.

For example, if Knop et al. (2017, p. 3) defined 'Structure' as communication systems, authority systems and workflow systems, which include both normative dimension (values, norms and general role expectations) and behavioural dimension (behaviour patterns, communication, authority), and the governance term according to Blohm et al. (2018, 7 f.) subsumes structuring roles and responsibilities, formal and informal rules, norms and regulations, measures to control outcomes, communication processes and matters of task allocations to achieve a crowdsourcer's goal, the question arises as to what is explicitly not included? The breadth of the proposed definitions makes it impossible to figure out what is actually meant and how one differs from the other.

Of course, the aim to initially propose definitions that are rather comprehensive and wide is understandable and inevitable when approaching a new phenomenon. It is, however, desirable to condense the initial uncertainty into clarity. As already mentioned in the introduction, it may be useful to choose interdisciplinary approaches in order to examine whether existing knowledge, for example, in the form of existing theoretical and terminological applications, is suitable for the present case. At this point, a discussion of the significance and scope of control categories in crowdsourcing appears to be urgently required. Since a lot of the introduced aspects of IC - frameworks, mechanisms, elements and componentsseem to circle around the idea of steering or managing a crowdsourcing process as an action which is described by the term governance, understanding the latter must be the focus.

Of interest are the relationships between control subject and control object, as they are reflected in the governance definitions of crowdsourcing presented above. It is important, however, to first define the meaning and scope of the term governance itself. Since the only substantial reference to governance, namely, the reference to Lynn et al. (2001), points in the direction of political science, the following section will examine the range of definitions within this discipline and examine their transferability. 


\subsection{Governance in Political Science}

According to Peters (2010, p. 2) the concept of governance can be considered as the most fashionable term-perhaps even a 'fetish'-in political science in recent years. The ambiguity of the concept is the reason for its success, because (Peters 2010, ibid.):

[...] it can be shaped to conform to the intellectual preferences of the individual author and therefore to some extent obfuscates meaning at the same time that it perhaps enhances understanding.

The scope of the governance concept can be extended almost arbitrarily by additional attributes (Offe 2009, p. 557). One can find texts about 'sectoral governance', 'good governance', 'corporate governance', 'public governance', 'multilevel governance', 'sustainable governance', 'global governance', 'environmental governance', 'cultural governance', 'earth system governance' or 'polycentric governance in telecoupled resource systems' to name but a few (Biermann et al. 2019; Newig et al. 2019; Brunnengräber et al. 2004; Grande 2012). Is governance therefore the all-purpose weapon for every kind of (social) regulatory problem as Grande (2012, p. 566) suspects? In fact, although it is a concept that is acknowledged as being unclear, fundamental common features in the characteristics of governance applications can be identified (von Blumenthal 2005; Lembcke et al. 2016).

It is clear that even if 'control' and 'governance' are used interchangeably at times, such an equivalent would imply that governing and governance are the same (Mayntz 2004). However, in contrast to their historical application, governance and governing cannot be applied synonymously in the sense of a hierarchy-bound control ideal, because, as will be shown, governance means control as cooperation and coordination (Mayntz 2008, 45). Thus governance concepts in political science are more than just 'empty signifiers' (Offe 2009). Following Grande (2012, 566 f.) there is a conceptual core that can be described as the common denominator of the various approaches, which can be summarized on the basis of five characteristics:

The first and most important feature is the emphasis on non-hierarchical forms of production of public goods.

Second, this is associated with a critique of the state as the exclusive producer of public goods. What is characteristic of governance concepts [...] is that non-state actors and organizations $[\ldots]$ are gaining in importance.

This critique of hierarchies as a control principle and the inclusion of private actors in the production of public goods is interpreted as a necessary consequence of interdependence, which would be the third common feature.

Fourth, because of this increasing interdependence, but also because of the loss of significance of territorial and functional boundaries for action, the complexity of political action has increased considerably.

[...] All of this has resulted in a considerable increase in the necessity and importance of cooperation and coordination between a wide range of actors.

The empirical origin of governance concepts lies, inter alia, in the observation of increasing interdependencies between social subsystems and territorial levels of action (Grande 2012, ibid.). In the second half of the last century, the understanding 
of a traditional conceptualization of the public sector, according to which the state as the most important actor influences the economy and society, came under pressure. Part of the burden on national governments has resulted in the increased importance of international policy spheres and a diminished ability of national governments to protect their economies and societies from global pressures or to tackle global challenges alone (Peters and Pierre 1998, p. 223). In addition, the arenas and structures of negotiation processes within national arenas are subject to increasing demands for dialogue and participation between state and society, state and the economy, state and non-governmental organizations and national and supranational or international institutions. The European Union, while questioning the classical unity of law and politics in the nation state and leading to a multi-level system with a wide variety of constellations of actors and institutional architectures, is repeatedly cited as an example for this (Mayntz 2008; Brunnengräber et al. 2004; Grimm 2001; Peters and Pierre 1998).

An essential contribution to governance research is the argument that the development towards governance is a three-step process from 'planning' to 'control' to 'governance' (Schuppert 2016; Mayntz 2008; Grande 2012). While at first planning was at the centre of a state that actively controlled all social processes, planning semantics were soon replaced by control semantics and transformed into a control theory (Steuerungstheorie) (Schuppert 2016, p. 151). In control theory, the concept of hierarchical control is the fundament of the analytical framework. (Mayntz 2008, 43):

This concept allowed a clear distinction to be made between control subject and control object; control objects are social subsystems or groups whose behaviour is to be steered in a certain direction.

If the central assumption of control theory is therefore the existence of a control subject, it is important to realize that governance is understood as something fundamentally different. In governance regimes, so Grande (2012, p. 581),

[...] there is no actor any more who could function as an autonomous controlling instance of the overall process - neither real nor imaginary. [...] But if such a steering body no longer exists, then it no longer makes sense to speak of steering — and in cases where such a steering body still exists, governance should not be spoken of.

Even a nonhierarchical relationship between state and society is understood as 'control' in the sense of control theory (Grande 2012, p. 584). The intentional control desire by a control subject remains essential. Even though governance can be defined as 'the intentional regulation of social issues' (Mayntz 2008, 55), it remains open how 'in complex, dynamic governance structures one can sensibly speak of control intentions' (Grande 2012, p. 581). 


\subsection{Interim Conclusion}

If the understanding of governance presented here in the context of political science is transferred to the de facto application within the crowdsourcing literature, some problems arise. In fact, as described before, the steering intention is an essential feature not only of the crowdsourcing process itself, but-more importantly-of the descriptive intention for which the word governance is used. As already stated, all descriptive approaches to crowdsourcing have in common that they assume a claim to control that is bound by the goal of achieving a 'desired solution' (Pedersen et al. 2013 , p. 582) that is 'the crowdsourcer's goal' (Blohm et al. 2018, p. 7). Functionally, participants in crowdsourcing can always be divided into two roles: the 'crowdsourcer' and the 'crowdsourcee'. The 'crowdsourcer' is a client who is looking for a solution to a given problem; the crowdsourcees are members of the crowd who are supposed to work out a solution (Leimeister et al. 2015). This applies to both external and internal crowdsourcing, both of which must be regarded as a closed system in this context. Thus, they fit ideally into the understanding of control subject ('crowdsourcer') and control object ('crowdsourcee'), as a group whose behaviour is to be steered in a certain direction), as assumed in control theory. This understanding is clearly reflected in the following governance definition for crowdsourcing (Pedersen et al. 2013, p. 582):

Governance is the actions and policies employed to effectively manage the crowd and steer them toward the desired solution.

Clearly governance for the description of crowdsourcing systems here actually means control. However, in the sense of a political science application, this terminology cannot be meaningfully transferred because, despite the diversity of governance applications, governance explicitly means something other than linear, hierarchical control relations (see above).

Since it has been established that the research on external and internal crowdsourcing pursues a strongly innovation-centred approach, which points to a predominant examination by economic and business management scientific disciplines, it shall be investigated at this point whether interdisciplinary governance research in economics offers further definitions that can support the current understanding of the application of governance for crowdsourcing.

\subsection{Governance in the Economy}

Two general governance concepts in economics are briefly outlined below. On the one hand, the concept of 'corporate governance' and on the other hand, theoretical approaches to 'economic governance'. While debates in the context of individual companies are outlined within the first, the second aims at macroeconomic understandings (Brunnengräber et al. 2004, p. 22). For Lindberg et al. (1991, 5 f.), 
'Economic governance' can be described as a phenomenon at the meso-level, i.e. in industrial sectors. Governance there can be seen as

[...] a matrix of interdependent social exchange relationships, or transactions, that must occur among organizations, either individually or collectively, in order for them to develop, produce, and market goods and services. Thus, governance is an extremely complex phenomenon.

Like within the political science approach, the aspect of interdependence is also brought to the fore here (Brunnengräber et al. 2004, p. 24). The difference is that the objective is not to regulate social issues in a way that is in the public interest but rather to develop, produce and market goods and services (Lindberg et al. 1991, p. 6; Mayntz 2008, 45 f.).

Under 'corporate governance', various framework legislations and reporting obligations are subsumed as a legal and factual regulatory framework. The approach is also concerned with the question of-responsible, sustainable, long-term value creation-oriented-corporate management and control (World Bank 1996, XIV; Brunnengräber et al. 2004, p. 7). Following Bainbridge (2002, p. 15), all corporate governance concepts have one thing in common:

They strive to answer two basic sets of questions: (1) As to the means of corporate governance, who decides? In other words, when push comes to shove, who ultimately is in control? (2) As to the ends of corporate governance, whose interests prevail? When the ultimate decisionmaker is presented with a zero-sum game, in which it must prefer the interests of one constituency class over those of all others, which constituency wins?

At its core, therefore, corporate governance is also concerned with the problems of control intentions and hierarchies in a multi-level system. This is particularly evident in the case of stock corporations, shareholder claims and multinational companies with many regulatory and territorial levels of action. Even though the corporate constitution of companies is more reminiscent of the unity of law and politics in the sovereignty of the nation state in the late nineteenth and early twentieth centuries, it is also true for companies that the arenas and structures of negotiation processes are subject to major changes. Finally, the term 'corporate governance' does not refer to the internal order, i.e. the corporate constitution, but addresses problems within the framework of the integration of the company into its environment (Werder 2018).

In summary, it can be stated that-even though governance research is much less pronounced in economics and heterogeneous conceptual approaches can be observed for both disciplines - the traditional division of disciplines into political and economic subsystems is blurred in governance research (Brunnengräber et al. 2004, p. 24):

The market, state and society are increasingly being placed in relation to one another by referring to the interdependencies and complex interdependencies between the social spheres. The various levels and systems of action (multi-level governance) are important in both political and economic concepts. The consideration of many actors and forms of interaction is addressed in the same way as the problem constellations, which are increasingly differentiating globally. 


\subsection{Lessons from Governance Research}

For the discussion at hand, neither economic nor political science definitions for governance support the proposed use of the term governance for the description of control activities in crowdsourcing systems. More so, analysing the governance discourse in those disciplines opens a new perspective which renders it necessary to save the term in its political and economic meaning for a later use in the description of crowdsourcing.

If governance concepts, as models of new cooperative network management, are expressions of 'long-term structural changes in the modes of production of collective goods in modern contemporary societies' (Grande 2012, p. 585; Mayntz 2008, 46), then it makes sense to take a closer look at crowdsourcing itself as an expression of this structural change. Crowdsourcing then becomes an indicator of a systemic transformation through digitization, in which internal crowdsourcing possibly describes changes in the internal organization and external crowdsourcing possibly describes the relocation of work from the classical company organization. If such a transformation process - which cannot (yet) be observed-leads to a situation in which the roles 'crowdsourcer' and 'crowdsourcee' can no longer be assigned to a subject and object relation in a control-theoretical sense, i.e. if crowdsourcing creates 'relatively autonomous, functional subsystems' (Mayntz 2008, 48), then it is not only sensible but necessary to introduce the governance concept in the sense of crowd governance for steering purposes in multi-level crowdsourcing systems.

A similar approach is introduced by Fenwick et al. (2018, p. 9), albeit from a legal, market regulatory perspective, that propose to further the approach of corporate governance towards a platform governance:

Given the proliferation of platforms, we seem to be living through a shift from a world of firms to a new world of platforms. In the same way that the 'firm' came to replace 'contracts' for many business activities in the context of the industrial revolution, 'platforms' are now replacing 'oldworld firms' in the context of the digital transformation.

In order to meet the resulting challenges for the economy, Fenwick and Vermeulen (2019, p. 2) deem it necessary to develop modern guidelines and regulations in the sense of 'corporate governance' as a 'platform governance'.

With regard to the influence of crowdsourcing on the future constitution of companies (and its effect on hierarchy-dependent steering aspirations), some considerations have also been made by Schröter (see chapter 'Good Practice at GASAGGroup: Recommendations for the Application of Internal Crowdsourcing from a Business Perspective'):

As virtual transaction spaces and platforms that were previously standalone grow together over time, new potentials of crowdsourcing unfold as part of modern crowdworking. Thinking and working in an order-related manner as well as a move away from focussing on purely vertical towards mainly horizontal value-creation chains in future, together with models of partially autonomous and agile working, will lead to a dominant culture of crowdsourcing applications. The boundaries between internal and external crowdsourcing are becoming blurred and both dynamics will merge with one another. Due to the 
progressive removal of boundaries in company operations, the division between internal and external utilizations will slowly fade.

In order to be able to depict and describe such potential future phenomena in crowdsourcing system theory, the term governance, as it has been coined by political science during the last 50 years, may be appropriate and should consequently be reserved (Fig. 1).

\subsection{Crowdsourcing Management}

There is a clear recommendation that the term 'governance', as used in the definitions of crowdsourcing by Pedersen et al. (2013), Zogaj et al. (2014), Zuchowski et al. (2016) and Blohm et al. (2018), should be replaced by the word 'management'.

This applies consequently to the conceptions presented by Pedersen et al. (2013) and Zuchowski et al. (2016) with respect to model elements or components, here to the description of 'governance mechanisms' (Pedersen et al. 2013; Blohm et al. 2018) or 'crowdsourcing governance tasks' (Zuchowski et al. 2016).

It should be noted that it is not a question of replacing one term 'only' because another is more appropriate. Much more importantly, it is assumed that the future description of a crowdsourcing systems requires the description of a crowdsourcing governance and resulting governance mechanisms in the sense of an understanding shaped and presented by political and economic science. The term should in any case not be introduced to describe control principles and mechanisms, which of necessity would lead to misunderstandings, especially in interdisciplinary approaches (which constitute the norm for scientific approaches to crowdsourcing).

With regard to the question of how and whether already described subcategories and aspects of an IC System can be meaningfully described and placed in an orderly overall relationship, it is now advised to go back to the proposed description categories of an IC System for which management is anticipated. Earlier some subcategories and aspects for the description of a crowdsourcing system had been identified. (1) Crowdsourcing as a system or concept consists of framework conditions, elements or components (Pedersen et al. 2013; Zuchowski et al. 2016). These frameworks, elements and components, as proposed by Knop et al. (2017), can be interpreted through the lens of socio-technical systems theory, which is a first reference to suitable theory frameworks. (2) All approaches are united in that they presuppose a system inherent manoeuvrability towards a 'desired solution' (Pedersen et al. 2013, p. 582) that implicitly defines the purpose of the system, namely, to achieve 'the crowdsourcer's goal' (Blohm et al. 2018, p. 7). (New 3) In order to achieve this, as should be stated from now on, management is required. (New 4) Management, in turn, should be subdivided into individual mechanismsbased on suggestions by Zogaj et al. (2014) and Blohm et al. (2018)—or crowdsourcing management tasks, based on suggested crowdsourcing governance tasks by Zuchowski (2016). (New 5) A functional and structural distinction is made 


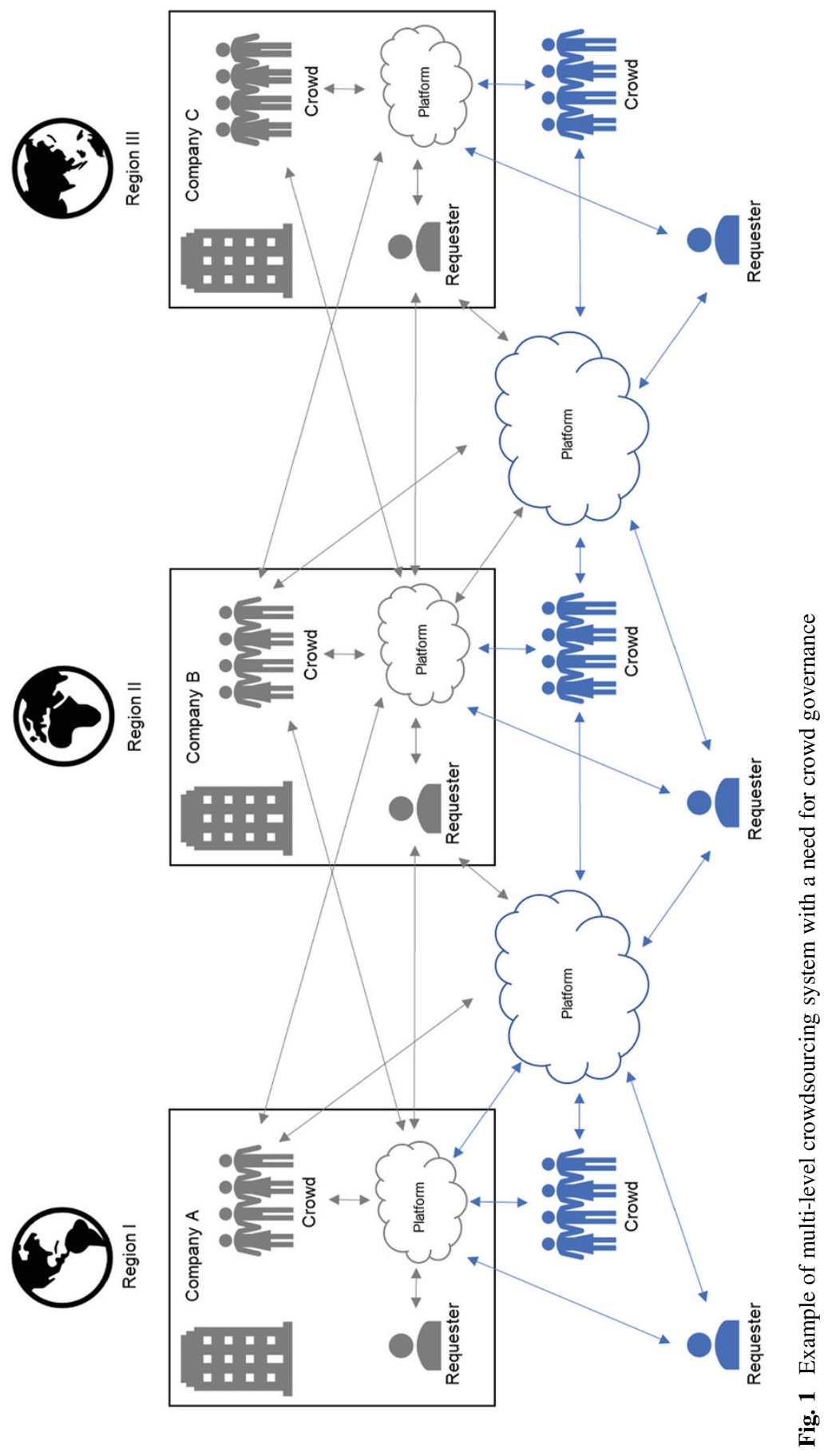


between external and internal application and implementation of crowdsourcing management (Zuchowski et al. 2016; Knop et al. 2017).

To start with the derivation of constitutive factors for an IC System, a closer look will now be taken at the meaning of the supposed framework conditions, elements, components and theory frameworks suggested above.

\subsection{Crowdsourcing Theory Frameworks}

Starting with suitable framework ascriptions to internal crowdsourcing, two kinds of frameworks have been mentioned so far: theory frameworks and systemic framework conditions.

With respect to theory frameworks, their scope and application are uncontroversial. As compiled by Wedel (2016, $13 \mathrm{f}$.), the following are summarized: for Ostrom (2007, p. 25) frameworks provide a metatheoretical language that can be used to compare theories. While frameworks bound inquiry and focus attention on critical features of the social physical landscape by specifying classes of variables and their interrelations, they cannot in and of themselves provide explanations and predictions (Schlager 2007, p. 293). It is theories that 'place values on some of the variables identified as important in a framework, and make predictions about likely outcomes' (Schlager 2007, p. 296). Theories are compatible with different frameworks (Ostrom 2007, p. 26). As identified by Moravcsik and Schimmelfennig (2009, p. 68), sometimes a minimum of three theories, organized in a multistage model, are required to avoid monocausal interrelations. Indeed this can be favourable to allow for counterfactual reasoning and avoid serious analytical fallacies (Ladrech 2010, pp. 40-41).

With respect to the subject matter of internal crowdsourcing, a couple of theories and respective schools of thought can be identified that provide a metatheoretical language and focus attention on IC. For the sake of this article, it is rather obvious that aspects of political science theory (here e.g. and in particular control/hierarchy theory and governance theories with respect to variables in light of multi-level, international, supra- and international system descriptions) should to be incorporated into a crowdsourcing theory framework. As mentioned earlier, Knop et al. (2017) and Knop and Blohm (2018) suggest incorporating sociotechnical systems theory (STS) into an overall framework, because researchers in the past analysed phenomena that are similar to internal crowdsourcing-where complex interactions between humans, technology and environments were observed-through the lens of STS. Here the metatheoretical language informs the concept of socio-technical components as applied within crowdsourcing (Knop et al. 2017, pp. 2-3). Based on Reichwald et al. (1998), it is Simmert et al. (2020) who suggest that the effect of internal crowdsourcing be analyzed in terms of key performance indicators by way of an extended economic efficiency analysis taking into account qualitative benefits (time, quality, flexibility, human situation) in addition to various cost aspects. 
While the identification of all distant theory remarks ever applied in the context of internal crowdsourcing research is beyond the scope of this article and would be a questionable exercise in terms of its informative value, some conclusions can be drawn at this stage, nonetheless. While Simmert et al. (2020) approach the subject matter through an information systems lens, with STS theory Knop et al. (2017) chose the lens of organizational sociology, while the bulk of authors analysed by Pohlisch (see chapter 'An Introduction to Internal Crowdsourcing') chose an economic, innovation-centred lens. The authors of this article are certainly shaped by a social sciences approach (political science and sociology). If future researchers would acknowledge this interdisciplinary, multistage framework for the analysis of internal crowdsourcing, drawing on economics, social science and computer science approaches, thereby allowing for counterfactual reasoning while avoiding serious analytical fallacies, it could lead to concise, helpful and robust research results. This is only true, however, if such an interdisciplinary theory framework is based on and united by binding, consensus-based applications of system categories and descriptions. To arrive at such a consensus, it certainly helps to understand by what theory frameworks the metatheoretical language is informed. It is then necessary to agree which terminologies (including their theory inherent and discipline dependent understanding) are accepted and applied for the description of IC Systems.

\subsection{IC Framework Conditions}

In order to finally approach a system description for IC, it is important to understand where the system begins and where it ends, which aspects lie outside the system and which components are part of the system.

When Pedersen et al. (2013) suggest a first conceptual model they identified the elements 'problem', 'people', 'governance', 'process', 'technology' and 'outcome' as relevant categories. Zuchowski et al. (2016, 168 f.) refer to these elements and conceptual model as a 'general crowdsourcing framework' and adopt it as a 'conceptual framework for internal crowdsourcing' consisting of various components (problems component, governance component, people component, IT component, process component and outcome component) (Zuchowski et al. 2016, ibid.). Following this understanding, the framework seems to represent the system itself. Figures in respective research present the categories and elements as part of a closed system (Pedersen et al. 2013, p. 3; Zuchowski et al. 2016, p. 170).

This understanding seems to originate from computer science where, based on Johnson and Foote (1988), the design of a program is described in terms of program components, based on a collection of abstract classes and an object-oriented abstract design, which is also called framework. A framework is therefore an abstract design for a particular kind of application. For Dietzsch (2002, p. 77) frameworks are then abstract architectures, i.e. reference architectures for families of application systems. 
While there is generally no reason to oppose incorporating this computer scientific understanding into an IC theory framework, and therefore regard a possible IC System as an IC Framework, two problems arise. First, the proposed components problem (input) and outcome are of a processual rather than architectural nature and should not be regarded as an inherent aspect of either a framework or a system, but, quite literally, as input and output of it. Secondly, an IC System itself has framework conditions which indeed influence the system but are not part of the system itself. This ultimately would add a framework to the framework, which could lead to terminological confusion.

As internal crowdsourcing takes place within a company (see chapter 'An Introduction to Internal Crowdsourcing' and 'Managing the Crowd-A Literature Review of Empirical Studies on Internal Crowdsourcing'), we identify and suggest three framework conditions with relevance to an IC System: external framework conditions, internal framework conditions and IC strategy framework conditions, with the latter two being part of an overall intracompany-specific environment.

External framework conditions subsume all external socio-economic aspects that shape a company's environment. Those are market, politics, law and regulations as well as society. We proceed from the assumption that it makes a difference to the particular IC System design whether internal crowdsourcing is applied in a market environment shaped by, e.g. grid-bound commodities (such as energy or railway markets), knowledge economies or various other products or service industries. Accordingly, different markets are subject to different degrees of political scrutiny and market regulation. The military industrial complex, the health sector or educational sector, to name but a few, are characterized by quite different requirements (e.g. national interest, protectionism, public welfare) and respective public and general interests. Practically this might favour or restrict, e.g. certain aspects of information and exchange flows within the crowd or between crowdsourcer and crowdsource which, in turn, will affect the IC System. To our knowledge, none of the proposed IC concepts or frameworks address these external extra-company framework conditions explicitly.

When Knop et al. (2017, p. 3) introduce the environment component they refer to those conditions that describe 'to what extent the internal crowdsourcing takes place in a certain organizational setting' which, according to our understanding, would be internal framework conditions. These conditions are shaped by respective business models, organizational structures, applied processes, given infrastructures (including in particular IT) and corporate culture (see also Astor et al. 2016; Kaiser et al. 2012; Hochfeld et al. 2014). Again, we assume that aspects such as, inter alia, company size (multinationals, SMEs, start ups, etc.), business layouts (shareholder driven, family business, social business, non-profit, etc.), application environments (hightech, $R \& D$ driven, not $R \& D$ driven), culture (high performance, conformist, traditional, change oriented, etc.) and leadership style (authoritarian leadership, cooperative leadership, participatory leadership, delegating leadership, etc.) influence aspects of a particular IC System design. 
Finally, against the backdrop of external and internal framework conditions, it is the strategy framework that most decisively influences the application design of an IC System. Here objectives of and strategies for IC are defined. As an important finding from previous research (Ulbrich and Wedel 2019), the identified and considered target dimensions of IC applications shape its design. Dimensions such as employee participation, employee qualification or product, process and service innovation might lead to different processes (e.g. with respect to task typologies) and activities (assigned tasks and roles) within the IC System. This is equally important for potential works agreements for IC between trade unions and employers which in themselves define yet another framework for the application of IC within a company, such as has been the case within the ICU Research Project (Otte and Schröter 2019).

\subsection{IC System}

While framework conditions influence the application design of internal crowdsourcing, they do not alter nor change the fundamental logic of an IC System. We argue that each IC System consists of three components: process, activity and information technology.

We adopt the notion of an IC System as an STS system where all three components: process, activity and information technology are interdependent and where all components and interdependencies are distinct and describable.

Building on Pedersen et al. (2013) and Zuchowski et al. (2016), we would suggest that the process and technology components for an ideal typical IC System be adopted while neglecting the notion of a distinct problems, people, governance and outcome component. While, as stated above, problem and output are inputs and outputs to and of the system, governance could only exist as management and would be located in the intersection of the components activity and process, while people would be subsumed within the overall component activity (with respect to assigned tasks and roles).

With respect to Knop et al. (2017), we suggest that the STS approach and the technology component be adopted while neglecting the actors, task, structure and environment component. While the actors and task component can be subsumed within the activity component, structures and environments really refer to the internal framework conditions in the company with relevance for the IC System.

We argue that all component aspects described by Pedersen et al. (2013), Zuchowski et al. (2016) and Knop et al. (2017), which are neither part of the framework conditions (see above) nor input or output to and of the process flow, can be subsumed within these three overall components or located within the interplay of these three components. A detailed description of the component 'activity' and 'process' can be found in chapter 'Systematization Approach for the 


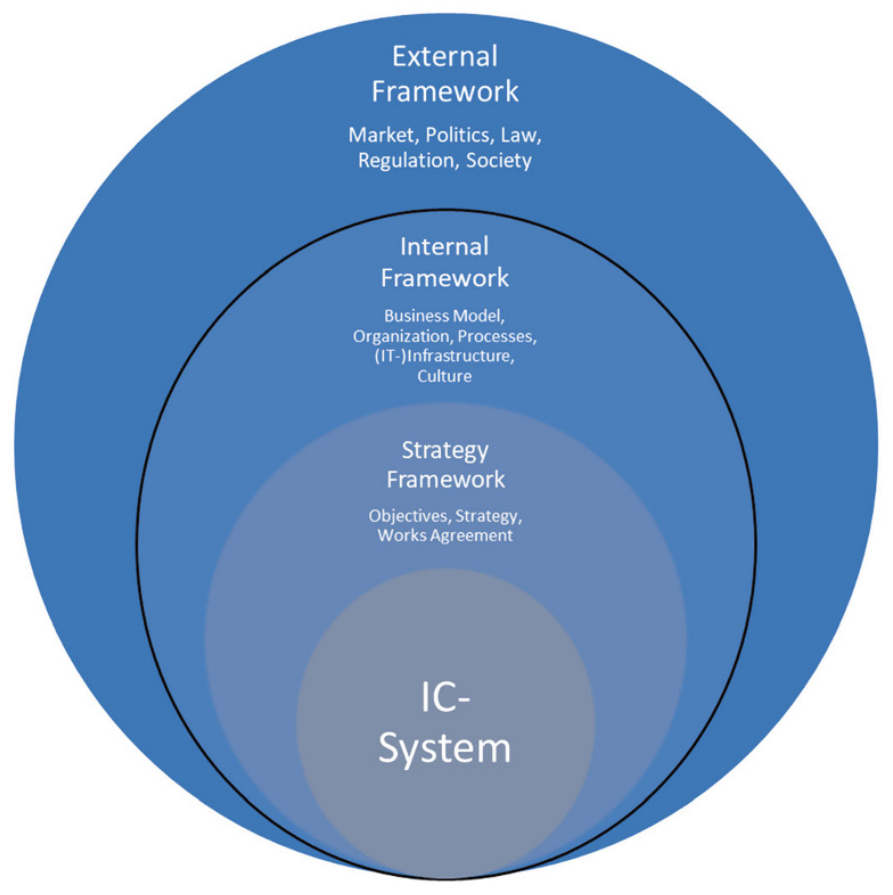

Fig. 2 Framework conditions for internal crowdsourcing

Development and Description of an Internal Crowdsourcing System' (Fig. 2). Further aspects with respect to IT implications and generic or specific crowd technology architectures for internal crowdsourcing can be found in chapter 'Design of a Process and Role Model for Internal Crowdsourcing' (Fig. 3).

Finally, we suggest that this three-component logic constitutes a simple yet solid basic IC System which can serve as a fundament for the description of theoretical IC principles. It is this three-component principle that is reflected in the IC definition by Zuchowski et al. (2016), whereas IC is an 'IT-enabled group activity based on an open call for participation in an enterprise'. Accordingly, we would argue the three components reflect this definition in so far as IC is in principle an IT-enabled activity based on a process.

Whether the interplay of the components, e.g. with respect to activity and process, is defined by five management challenges and mechanisms (Pedersen et al. 2013), six crowdsourcing management tasks (Zuchowski et al. 2016) or 21 management mechanisms (Blohm et al. 2018) are beyond the scope of this article and up for future discussion. It is, however, now of consequence for the suggested principle threecomponent layout of a basic IC System. 


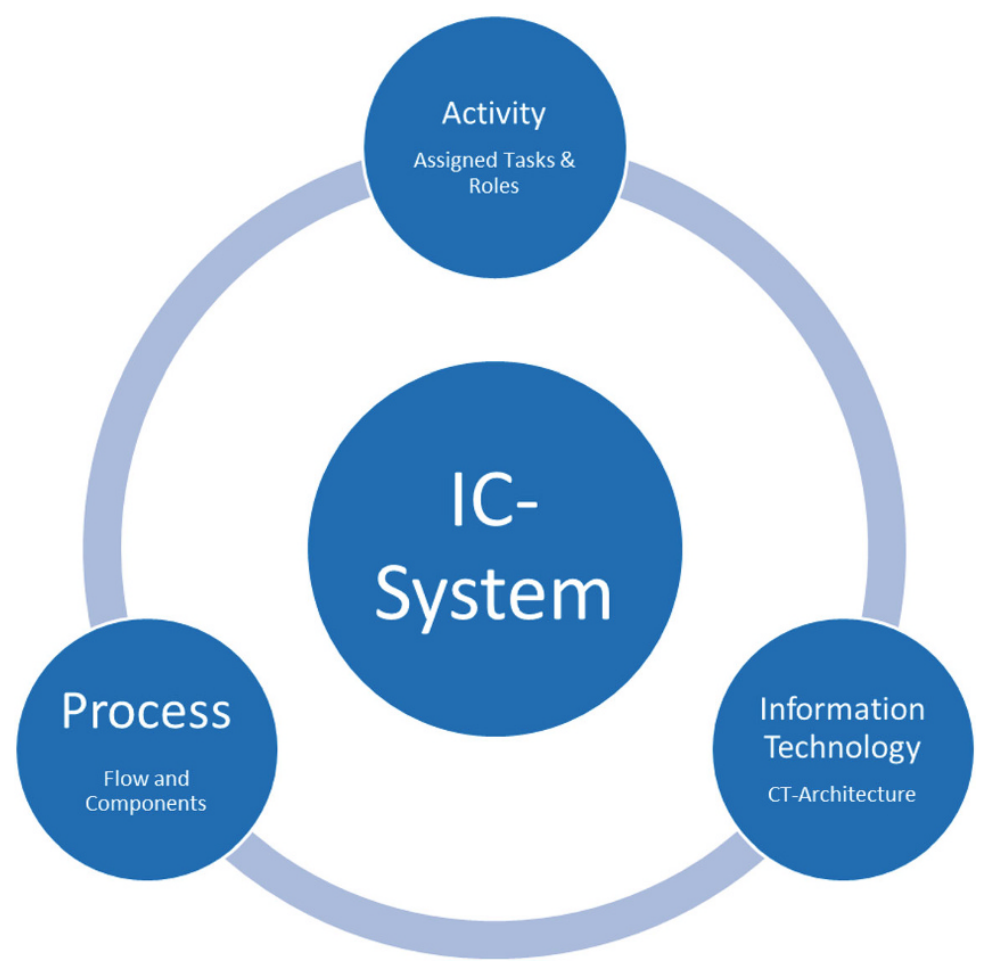

Fig. 3 Basic IC system (three components)

\section{Conclusion and Suggestions}

Considering the overall objective to systematize approaches towards developing a crowdsourcing system with binding system descriptions, the following is suggested in light of the deductions presented above:

1. Current IC theory frameworks are informed by an interdisciplinary, multistage analysis framework drawing on theories and leading to a meta-theoretical language informed by economics, social science and computer science approaches.

2. Each IC System consists of three components: process, activity and information technology. All additional aspects referred to as components in the IC literature that are neither part of the framework conditions nor input or output to and of the process flow can be subsumed within these three overall components or located within the interplay of these three components.

3. Every IC System is exposed to framework conditions: external, internal and strategy framework conditions, with the latter two describing overall intracompany framework conditions. While framework conditions influence the application design of internal crowdsourcing, they do not alter or change the fundamental logic of an IC System. 
4. IC is characterized by the logic of a system-inherent manoeuvrability towards a desired solution which is clearly attributed to a directional relationship (crowdsourcer $\rightarrow$ crowdsourcee) and shaped by management processes.

5. There is a functional and structural difference between internal and external applications of crowdsourcing and crowdsourcing management.

6. Neither internal nor external crowdsourcing applications can be described through a governance perspective.

7. Potential future multi-level crowdsourcing systems, within which directional dependencies (crowdsourcer $\rightarrow$ crowdsourcee) can no longer be clearly attributed, ought to be comprehended through a governance perspective.

The guiding questions have been: (How) Can the already described subcategories and aspects of an IC System be meaningfully described and placed in an orderly overall relationship? What needs to be added to the existing system descriptions, if at all?

As summarized above, we propose the terminologies 'IC Theory Framework', 'IC Framework Conditions' (external, internal and strategic) and 'IC System' (with the components process, activity and information technology) as a first approach to binding system descriptions. With respect to existing research we consider the actual IC System - that is sometimes referred to as a framework, which we do not recommend for concern it might cause confusion - to be rather simple and concise, consisting 'only' of three components (see above). We attribute many aspects elsewhere labelled as framework or system components to the framework conditions (as explained above) because, while these referred to circumstances are influencing the application design of IC, they do not constitute the system itself. We finally highly recommend that future crowdsourcing researchers adopt the terminological distinction and respective application between crowdsourcing governance and management in the future discourse.

This first approach towards the development of a crowdsourcing system with binding system descriptions can only be considered an initial contribution towards a needed theory-bound discussion with respect to the phenomenon of crowdsourcing.

\section{References}

Astor M, Rammer C, Klaus C, Klose G (2016) Innovativer Mittelstand 2025-Herausforderungen, Trends und Handlungsempfehlungen für Wirtschaft und Politik: Studie im Auftrag des Bundesministeriums für Wirtschaft und Energie. https://www.bmwi.de/Redaktion/DE/ Publikationen/Studien/studie-endbericht-innovativer-mittelstand-2025.html. Accessed 3 Feb 2020

Bainbridge SM (2002) Director primacy: the means and ends of corporate governance. SSRN Electron J. https://doi.org/10.2139/ssrn.300860

Baxter G, Sommerville I (2011) Socio-technical systems: from design methods to systems engineering. Interact Comput 23(1):4-17. https://doi.org/10.1016/j.intcom.2010.07.003 
Beese J, Kazem H, Aier S (2015) On the conceptualization of information systems as sociotechnical phenomena in simulation-based research. https://pdfs.semanticscholar.org/63ed/ 4e594c732636f2b52327efee89fd288b557e.pdf

Biermann F, Betsill MM, Burch S, Dryzek J, Gordon C, Gupta A, Gupta J, Inoue C, Kalfagianni A, Kanie N, Olsson L, Persson Å, Schroeder H, Scobie M (2019) The Earth System Governance Project as a network organization: a critical assessment after ten years. Curr Opin Environ Sustain 39:17-23. https://doi.org/10.1016/j.cosust.2019.04.004

Blohm I, Zogaj S, Bretschneider U, Leimeister JM (2018) How to manage crowdsourcing platforms effectively? Calif Manag Rev 60(2):122-149. https://doi.org/10.1177/0008125617738255

Brunnengräber A, Dietz K, Hirschl B, Walk H (2004) Interdisziplinarität in der GovernanceForschung. https://www.ioew.de/publikation/interdisziplinaritaet_in_der_governance_ forschung/

Dahlander L, Frederiksen L, Rullani F (2008) Online communities and open innovation. Ind Innovat 15(2):115-123. https://doi.org/10.1080/13662710801970076

Dietzsch A (2002) Frameworks. In: Dietzsch A (ed) Systematische Wiederverwendung in der Software-Entwicklung. Deutscher Universitätsverlag, Wiesbaden, pp 77-89

Ebner W, Leimeister JM, Krcmar H (2009) Community engineering for innovations: the ideas competition as a method to nurture a virtual community for innovations. R\&D Manage 39 (4):342-356. https://doi.org/10.1111/j.1467-9310.2009.00564.x

Fenwick M, Vermeulen EPM (2019) A sustainable platform economy \& the future of corporate governance. SSRN Electron J. https://doi.org/10.2139/ssrn.3331508

Fenwick M, McCahery JA, Vermeulen EPM (2018) The end of 'corporate' governance: Hello 'platform' governance. SSRN Electron J. https://doi.org/10.2139/ssrn.3232663

Garcia Martinez M (2017) Inspiring crowdsourcing communities to create novel solutions: competition design and the mediating role of trust. Technol Forecast Soc Change 117:296-304. https://doi.org/10.1016/j.techfore.2016.11.015

Grande E (2012) Governance-Forschung in der Governance-Falle?-Eine kritische Bestandsaufnahme. Politische Vierteljahresschrift 53(4):565-592. https://doi.org/10.5771/ 0032-3470-2012-4-565

Grimm D (2001) Die Verfassung und die Politik: Einsprüche in Störfällen. Beck, München

Hochfeld K, Kaiser S, Schraudner M (eds) (2014) Unternehmenskulturen verändern-Vielfalt erreichen. Fraunhofer, Stuttgart

Johnson R, Foote B (1988) Designing reusable classes. J Object Orient Program 1(2):22-35

Kaiser S, Hochfeld K, Gertje E, Schraudner M (2012) Unternehmenskulturen verändernKarrierebrüche vermeiden. Fraunhofer, Stuttgart

Keinz P (2015) Auf den Schultern von ... Vielen! Crowdsourcing als neue Methode in der Neuproduktentwicklung. Schmalenbachs Zeitschrift für betriebswirtschaftliche Forschung 67 (1):35-69. https://doi.org/10.1007/BF03372915

Knop N, Durward D, Blohm I (2017) How to design an internal crowdsourcing system. https:// www.alexandria.unisg.ch/252020/1/JML_672.pdf

Ladrech R (2010) Europeanization and national politics. Palgrave Macmillan, Basingstoke, Hampshire

Leimeister JM, Zogaj S, Durward D (2015) New forms of employment and IT—crowdsourcing. In: Conference of the regulating for decent work network.

Lembcke OW, Ritzi C, Schaal GS (eds) (2016) Zeitgenössische Demokratietheorie. Springer Fachmedien Wiesbaden, Wiesbaden

Lindberg LN, Campbell JL, Hollingsworth JR (1991) Economic governance and the analysis of structural change in the American economy. In: Campbell JL, Hollingsworth JR, Lindberg LN (eds) Governance of the American economy. Cambridge University Press, Cambridge, pp 3-34

Lynn LE, Heinrich CJ, Hill CJ (2001) Improving governance: a new logic for empirical research. Georgetown University Press, Washington, DC

Markus ML (2007) The governance of free/open source software projects: monolithic, multidimensional, or configurational? J Manag Govern 11(2):151-163. https://doi.org/10. 1007/s10997-007-9021-x 
Mayntz R (2004) Governance Theory als fortentwickelte Steuerungstheorie? Max-Planck-Institut für Gesellschaftsforschung, Köln. http://hdl.handle.net/10419/44296

Mayntz R (2008) Von der Steuerungstheorie zu Global Governance. In: Schuppert GF, Zürn M (eds) Governance in einer sich wandelnden Welt. VS Verlag für Sozialwissenschaften, Wiesbaden, pp 43-60

Moravcsik A, Schimmelfennig F (2009) Liberal Intergovernmentalism. In: Wiener A, Diez T (eds) European integration theory. Oxford University Press, Oxford

Newig J, Lenschow A, Challies E, Cotta B, Schilling-Vacaflor A (2019) What is governance in global telecoupling? Ecol Soc 24(3). https://doi.org/10.5751/ES-11178-240326

Offe C (2009) Governance: an 'empty signifier'? Constellations 16(4):550-562. https://doi.org/10. $1111 / \mathrm{j} .1467-8675.2009 .00570 . x$

Ostrom E (2007) Institutional rational choice: an assessment of the institutional analysis and development framework. In: Sabatier PA (ed) Theories of the policy process, 2nd edn. Westview, Boulder, CO, pp 21-64

Otte A, Schröter W (2019) Lebende Konzernbetriebsvereinbarung als soziale Innovation: Internes Crowdsourcing in der GASAG-Gruppe. Bedeutung - Bewertung - Wortlaut. In: Schröter W (ed) Der mitbestimmte Algorithmus: Impulse zur Demokratisierung der Arbeitswelt 4.0. Talheimer, Mössingen-Talheim, pp 185-212

Palin K, Kaartemo V (2016) Employee motivation to participate in workplace innovation via in-house crowdsourcing. Eur J Workplace Innovat 2(2):19-40

Pedersen J, Kocsis D, Tripathi A, Tarrell A, Weerakoon A, Tahmasbi N, Xiong J, Deng W, Oh O, de Vreede G-J (2013) Conceptual foundations of crowdsourcing: a review of IS research. In: 2013 46th Hawaii international conference on system sciences (HICSS), Wailea, HI, USA, 07.01.2013-10.01.2013. IEEE, pp 579-588. https://doi.org/10.1109/HICSS.2013.143

Peters G (2010) Governance as political theory. http://regulation.huji.ac.il/papers/jp22.pdf

Peters BG, Pierre J (1998) Governance without government? Rethinking public administration. J Public Admin Res Theor 8(2):223-243. https://doi.org/10.1093/oxfordjournals.jpart.a024379

Reichwald R, Engelberger H, Moeslein K (1998) Telekooperation im InnovationstestStrategieorientierte Evaluation von Pilotprojekten. Wirtschaftsinformatik 40(3):214-222

Sabatier PA (ed) (2007) Theories of the policy process, 2nd edn. Westview, Boulder, CO

Schlager E (1995) Policy making and collective action: defining coalitions within the advocacy coalition framework. Policy Sci 28(3):243-270. https://doi.org/10.1007/BF01000289

Schlager E (2007) A comparison of frameworks, theories, and models of policy processes. In Sabatier PA (ed) Theories of the policy process, 2nd edn. Westview, Boulder, CO, pp 293-319

Schuppert GF (2016) Governance in der Demokratietheorie. In: Lembcke OW, Ritzi C, Schaal GS (eds) Zeitgenössische Demokratietheorie. Springer, Wiesbaden

Simmert B, Eilers K, Peters C, Leimeister M (2020) Interne Crowd Work als Baustein einer Empowerment-orientierten Arbeitsorganisation. In Daum M, Wedel M, Zinke-Wehlmann C, Ulbrich $\mathrm{H}$ (eds) Gestaltung vernetzt-flexibler Arbeit. Beiträge aus Theorie und Praxis für die digitale Arbeitswelt. Springer, Berlin

Thuan NH (2019) Business process crowdsourcing: concept, ontology and decision support. Springer, Cham

Ulbrich H, Wedel M (2019) Development of employee-friendly internal crowdsourcing is more than innovation management: first findings from the ICU application. https://www.researchgate. net/publication/333396719. Accessed 1 Oct 2019

von Blumenthal J (2005) Governance-eine kritische Zwischenbilanz. Zeitschrift für Politikwissenschaft 15(4):1149-1180

Wedel M (2016) The European integration of RES-E promotion: the case of Germany and Poland. Springer Fachmedien Wiesbaden, Wiesbaden

Werder A v (2018) Corporate governance: definition. https://wirtschaftslexikon.gabler.de/defini tion/corporate-governance-28617/version-367554. Accessed 19 Sept 2019

World Bank (1996) Governance: the World Bank's experience, 2nd edn. World Bank, Washington, DC 
Zhu H, Djurjagina K, Leker J (2014) Innovative behaviour types and their influence on individual crowdsourcing performances. Int J Innovat Manag 18(06):1-18. https://doi.org/10.1142/ S1363919614400155

Zhu H, Sick N, Leker J (2016) How to use crowdsourcing for innovation?: A comparative case study of internal and external idea sourcing in the chemical industry. In: Kocaoglu DF (ed) Technology management for social innovation: PICMET'16 : Portland international conference on management of engineering and technology: proceedings. IEEE, Piscataway, NJ

Zogaj S, Bretschneider U (2014) Analyzing governance mechanisms for crowdsourcing information systems: a multiple case analysis. In: Avital M, Leimeister JM, Schultze U (eds) ECIS 2014 proceedings: 22th European conference on information systems, Tel Aviv, Israel, 9-11 June 2014. AIS Electronic Library

Zogaj S, Bretschneider U, Leimeister JM (2014) Managing crowdsourced software testing: a case study based insight on the challenges of a crowdsourcing intermediary. J Bus Econ 84 (3):375-405. https://doi.org/10.1007/s11573-014-0721-9

Zuchowski O, Posegga O, Schlagwein D, Fischbach K (2016) Internal crowdsourcing: conceptual framework, structured review, and research agenda. J Inform Technol 31(2):166-184. https:// doi.org/10.1057/jit.2016.14

Dr. Marco Wedel is a Political Scientist (Dipl.rer.pol., Dr. phil.) and Senior Researcher at the Department of Vocational Education, Technology and Participation at the Technical University of Berlin. In addition to study visits to Boston, Constance and Berlin, he has worked in the Energy Sector (BASF) and in Science Management (Falling Walls Foundation), among other things. His current research activities focus on the topics future of work, entrepreneurship, digitalization and media competence. His long-term research focuses on European integration, democratic competence and sustainable development. Marco Wedel is co-editor of the science journal 'InnovationThe European Journal of Social Science Research'.

Hannah Ulbrich holds a Degree in Sociology (Dipl. Soz.-Bielefeld/Berlin) and is a Senior Researcher at the Department of Vocational Education, Technology and Participation at the Technical University of Berlin. There, she is the project leader of the BMBF- and ESF-funded research project 'ICU-Internal Crowdsourcing in Companies'. In addition to her work as a project manager, she is a scholarship holder of the Berlin Professional School of Economics and Law where she is currently completing a part-time MBA programme. Her research focus is on entrepreneurship and innovation, new work and agility and digital transformation and leadership.

Open Access This chapter is licensed under the terms of the Creative Commons Attribution 4.0 International License (http://creativecommons.org/licenses/by/4.0/), which permits use, sharing, adaptation, distribution and reproduction in any medium or format, as long as you give appropriate credit to the original author(s) and the source, provide a link to the Creative Commons licence and indicate if changes were made.

The images or other third party material in this chapter are included in the chapter's Creative Commons licence, unless indicated otherwise in a credit line to the material. If material is not included in the chapter's Creative Commons licence and your intended use is not permitted by statutory regulation or exceeds the permitted use, you will need to obtain permission directly from the copyright holder.

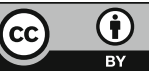

